\title{
Comparison of the pharmacokinetics and pharmacodynamics of biphasic insulin aspart and insulin glargine in people with type 2 diabetes
}

Received: 11 November 2005 / Accepted: 5 February 2006 / Published online: 5 April 2006

C) Springer-Verlag 2006

\begin{abstract}
Aims/hypothesis: The pharmacokinetic and pharmacodynamic properties of biphasic insulin aspart (BIAsp 30) (30\% soluble, $70 \%$ protaminated insulin aspart [IAsp]) and insulin glargine (IGlarg) were compared. Methods: Twelve people with type 2 diabetes took part in two 24-h isoglycaemic clamp studies, 1 week apart. Patients were randomised to treatment with $0.5 \mathrm{U} / \mathrm{kg}$ of BIAsp $30(0.25 \mathrm{U} / \mathrm{kg}$ at $08.30 \mathrm{~h}$ and $0.25 \mathrm{U} / \mathrm{kg}$ at $20.30 \mathrm{~h})$ or $0.50 \mathrm{U} / \mathrm{kg}$ IGlarg at $08.30 \mathrm{~h}$. Both insulins were given by subcutaneous injection into the anterior abdominal wall. The plasma glucose, glucose infusion rates, plasma insulin and C-peptide concentrations were measured. Results: All 12 patients were men; mean $( \pm \mathrm{SD})$ age was $58.8(8.9)$ years, BMI $31.0(3.0) \mathrm{kg} / \mathrm{m}^{2}$ and $\mathrm{HbA}_{1 \mathrm{c}} 7.1$ $(0.6) \%$. Plasma glucose was constant throughout the $24-\mathrm{h}$ clamp period. After each injection of BIAsp 30, glucose infusion rates increased, reaching a distinct peak approximately $3-5 \mathrm{~h}$ after injection. A much flatter postinjection profile was observed following IGlarg administration. Plasma insulin concentrations rose rapidly after each injection of BIAsp 30, reaching a distinct peak after approximately $2-3 \mathrm{~h}$. A flatter plasma insulin profile reached a plateau approximately 6-16 h after IGlarg administration. Plasma C-peptide fell below baseline after both injections of BIAsp 30 but remained unaltered after IGlarg injection. Conclusions/interpretation: The pharmacodynamic and pharmacokinetic profiles were 34 and $28 \%$, respectively, higher following equivalent doses $(0.5 \mathrm{U} / \mathrm{kg})$ of BIAsp 30 given as two split doses than following IGlarg given as a single daily dose.
\end{abstract}

\footnotetext{
S. Luzio $(\bowtie) \cdot$ G. Dunseath $\cdot$ R. Peter $\cdot$ V. Pauvaday

D. R. Owens

Diabetes Research Unit, Llandough Hospital,

Penlan Road, Penarth,

South Glamorgan, CF64 2XX, UK

e-mail: Luzio@Cardiff.ac.uk

Tel.: +44-29-20716921

Fax: +44-29-20350147
}

Keywords Biphasic insulin aspart - Insulin glargine · Isoglycaemic clamp · Pharmacodynamics ·

Pharmacokinetics - Type 2 diabetes

Abbreviations BIAsp: biphasic insulin aspart - GIR: glucose infusion rate · IAsp: insulin aspart - IGlarg: insulin glargine - OHA: oral hypoglycaemic agent $\cdot \mathrm{NPH}$ : neutral protamine Hagedorn $\cdot t_{\max }$ : time to reach maximum concentration

\section{Introduction}

Type 2 diabetes is a progressive disease with abnormalities in pancreatic beta cell function and cellular defects in insulin activity both in skeletal muscle and in hepatic cells, which deteriorate over time. Thus, treatment for people with type 2 diabetes must reflect the evolving pathophysiological process [1]. For many people with type 2 diabetes, insulin therapy is ultimately required in order to achieve satisfactory glycaemic control [2]. However, the introduction of insulin is often delayed unnecessarily in individual patients until progressive decline of beta cell function renders oral hypoglycaemic agents (OHAs) ineffective in maintaining satisfactory glycaemic control [3].

Once the decision to commence insulin therapy has been made, there are a number of options for the treatment regimen to be used in persons with type 2 diabetes [4]. Three recent studies have evaluated these different approaches using both human insulin and insulin analogues. A 24-week study [5] of 756 overweight patients with type 2 diabetes with inadequate glycaemic control $\left(\mathrm{HbA}_{1 \mathrm{c}}>7.5 \%\right)$ were continued on oral hypoglycaemic agents but received at bedtime either insulin glargine or human neutral protamine Hagedorn (NPH) in order to achieve fasting plasma glucose of $\leq 5.6 \mathrm{mmol} / 1(100 \mathrm{mg} / \mathrm{dl})$. Addition of either form of basal insulin produced a $\mathrm{HbA}_{1 \mathrm{c}}$ concentration of $7 \%$ in most patients, but there was significantly less hypoglycaemia in the patients receiving insulin glargine than in those receiving NPH. Raskin et al. [6] randomised patients failing on oral hypoglycaemic 
agents to receive either insulin glargine at bedtime or premixed $(70 \%$ protaminated insulin aspart $/ 30$ soluble insulin aspart) insulin twice a day for 24 weeks. Oral hypoglycaemic agents were stopped with the exception of metformin (optimised to 1,550-2,550 mg) and glitazones. The aim of the study was to achieve fasting blood glucose of $4.4-5.6 \mathrm{mmol} / 1(80-100 \mathrm{mg} / \mathrm{dl})$ in both groups, with the same target before evening meal in the patients taking premixed insulin. The results showed that patients receiving premixed insulin had a greater fall in $\mathrm{HbA}_{1 \mathrm{c}}$ compared with those receiving insulin glargine $(-2.8$ vs $-2.4 \%)$. However, there were more frequent hypoglycaemic events in the patients receiving premixed insulin twice daily. In a different study [7], two groups of patients with type 2 diabetes who were failing on oral hypoglycaemic medication were compared. In this 24-week study, one group received a morning injection of insulin glargine in addition to 3-4 mg glimeperide and $850 \mathrm{mg}$ or more of metformin. The other group had the oral medication discontinued and were started on twice daily injections of premixed human insulin $(70 \% \mathrm{NPH} / 30 \%$ regular). The glycaemic targets were to achieve a fasting glucose concentration of $5.6 \mathrm{mmol} / 1$ $(\leq 100 \mathrm{mg} / \mathrm{dl})$ and a similar target before evening meal in the group taking premixed insulin. In contrast to the previous study, results from this study showed that patients in the glargine plus OHA group had a statistically significant greater fall in $\mathrm{HbA}_{1 \mathrm{c}}(-1.6$ vs $-1.3 \%)$ and fewer hypoglycaemia events were observed.

Commonly used insulins for the initiation of insulin therapy are the premixed insulins, including biphasic insulin aspart (BIAsp) and the basal insulin, insulin glargine (IGlarg). The aim of this study was therefore to compare the pharmacokinetic and pharmacodynamic profiles associated with these two very different regimens for initiating supplementary insulin therapy in people with type 2 diabetes. This study compared the same total daily dose $(0.5 \mathrm{U} / \mathrm{kg})$ of one injection of IGlarg and two injections at $12 \mathrm{~h}$ intervals of BIAsp 30 during a 24-h isoglycaemic clamp in persons with type 2 diabetes.

\section{Subjects and methods}

\section{Patients}

Twelve men with type 2 diabetes treated with oral hypoglycaemic agents and with mean $( \pm \mathrm{SD}) \mathrm{HbA}_{1 \mathrm{c}} 7.1$ $(0.6) \%$ were included in the study. None had been treated previously with insulin or had severe complications of diabetes likely to interfere with the action of the study drugs. The study protocol was approved by the local research ethics committee and all patients gave written informed consent.

\section{Study design}

This was a randomised, open, single-centre, two-way crossover study. Eligible patients attended the Diabetes Investigation Unit on two separate study days between 6 and 27 days apart. Subjects were maintained on the same oral hypoglycaemic therapy throughout the study period, although the OHA medication was discontinued the night before each clamp and resumed the following day. On the first study day the subjects received either $0.5 \mathrm{U} / \mathrm{kg}$ of BIAsp 30, given as two doses $12 \mathrm{~h}$ apart $(0.25 \mathrm{U} / \mathrm{kg}$ at $08.30 \mathrm{~h}$ and $0.25 \mathrm{U} / \mathrm{kg}$ at $20.30 \mathrm{~h}$ ), or the same total dose $(0.5 \mathrm{U} / \mathrm{kg})$ of IGlarg at $08.30 \mathrm{~h}$, s.c. into the anterior abdominal wall. An isoglycaemic clamp was carried out during the following $24 \mathrm{~h}$. After a washout period of approximately 7 days, all 12 patients returned to the Diabetes Investigation Unit for a further study day, on which they received the comparator preparation.

\section{Clamp technique}

On each study day the patients attended the Diabetes Investigation Unit prior to $08.00 \mathrm{~h}$ following a $10 \mathrm{~h}$ overnight fast. Patients remained fasting and on bed rest throughout the study period. An intravenous cannula was inserted into the forearm for the purpose of administering $20 \%$ glucose as required to maintain plasma glucose at the basal level. A second cannula was inserted into a dorsal hand vein in the opposite arm for blood sampling. The hand was kept warm to allow arterialised blood sampling. Fasting samples were taken at 10 min intervals from -30 to $0 \mathrm{~min}$, following which a bolus dose of either $0.25 \mathrm{U} / \mathrm{kg}$ BIAsp 30 or $0.5 \mathrm{U} / \mathrm{kg}$ IGlarg was administered s.c. into a skin fold of the anterior abdominal wall. Patients randomised to BIAsp 30 received a second dose of $0.25 \mathrm{U} / \mathrm{kg} 12 \mathrm{~h}$ later. Blood samples for determination of plasma glucose concentrations were obtained at 10 min intervals throughout the 24-h period of the clamp. The glucose infusion rate (GIR) of $20 \%$ dextrose was adjusted manually every $10 \mathrm{~min}$ to maintain plasma glucose at fasting concentrations.

Similar frequent samples for determining plasma insulin and C-peptide concentrations were also taken during the 24-h period.

\section{Pharmacokinetic and pharmacodynamic assessments}

The AUCs of GIR, plasma insulin and C-peptide were calculated using the trapezoidal rule and compared during $24 \mathrm{~h}$ for the two treatments. The exogenous insulin contribution was estimated from the observed plasma insulin and C-peptide concentrations using the initial ratio method [8], based on the assumption that the insulin assay measures the circulating endogenous and exogenous insulin concentrations in an additive manner, using C-peptide as a measure of endogenous insulin secretion. The calculation is based on the ratio (F) between insulin and C-peptide concentrations during the initial $30 \mathrm{~min}$ basal period according to the following equation:

$$
I n s_{E X O G}=I n s_{O B S}-F \times C-\text { peptide }_{O B S}
$$


The terms Ins $_{\text {EXOG }}$, Ins $s_{\text {OBS }}$ and C-peptide ${ }_{\mathrm{OBS}}$ represent the estimated exogenous and observed insulin concentrations and the corresponding C-peptide concentration, respectively.

The maximum concentration of insulin and the time to reach maximum concentration $\left(t_{\max }\right)$ were calculated for the periods $0-12,12-24$ and $0-24 \mathrm{~h}$. Bioavailability was calculated on the basis of $\mathrm{AUC}_{0-24 \mathrm{~h}}$ for measured insulin concentration and for calculated exogenous insulin concentration.

\section{Analyses}

Plasma glucose was measured using a Yellow Springs glucose analyser (YSI2300; Yellow Springs Instruments, Aldershot, UK). Concentrations of plasma insulin and C-peptide were measured with immunoassays (MLT Research, Cardiff, UK). The cross-reactivity of human insulin, IAsp and IGlarg in the insulin assay was approximately $100 \%$.

\section{Statistical methods}

A power calculation based on a previous study showed that 12 people with type 2 diabetes needed to complete the study in order to have $80 \%$ power to detect a treatment difference of $23 \%$ in AUC-GIR ${ }_{0-24 \mathrm{~h}}$. All statistical significance tests were carried out at the $5 \%$ level and were two-sided. Statistical analysis was performed on all variables using an analysis of variance test suitable for the crossover design adopted. Treatment, period and treatment sequence with patient were factored into the statistical model. All clamp plasma glucose values were based on changes from the baseline value, taken to be the mean of the $-30,-20,-10$ and 0 min samples.

\section{Results}

Patients

The mean $( \pm \mathrm{SD})$ baseline characteristics of the 12 patients who completed the study were as follows: age 58.8 (8.9) years; BMI 31.0 (3.0) kg/m²; $\mathrm{HbA}_{1 \mathrm{c}} 7.1$ (0.6)\%. All patients were treated with OHAs before the start of the study (seven gliclazide, three repaglinide, one glimepiride, ten metformin).

During the isoglycaemic clamp study days, mean insulin doses were similar for BIAsp 30 (46.5 \pm 5.6 IU; range 36$50 \mathrm{IU})$ and IGlarg (46.5 $\pm 5.4 \mathrm{IU}$; range 37-50 IU).

Plasma glucose concentration during clamp

Fasting plasma glucose concentrations were similar on the BIAsp 30 and IGlarg study days $(7.7 \pm 0.5$ and $7.7 \pm$ $0.4 \mathrm{mmol} / \mathrm{l}$, respectively). Mean plasma glucose concen- trations during the 24-h clamp period (expressed as percentage of target glucose level) were similar for BIAsp 30 and IGlarg during the clamp (Fig. 1). Variations in glucose concentrations about the target value during the clamp (CV of deviation of all glucose values during the clamp period from the target value) were similar for the two insulins (6.3\% for BIAsp 30 and $4.3 \%$ for IGlarg). Mean changes in clamp plasma glucose concentrations, expressed as area under the glucose curve $(\triangle \mathrm{AUC})$, were 0.33 (SEM 0.21) mmol h $\mathrm{l}^{-1}$ for BIAsp 30 and 0.59 $(0.40) \mathrm{mmol} \mathrm{h} \mathrm{l}^{-1}$ for IGlarg $(p=0.59)$ for $\Delta \mathrm{AUC}_{0-12} \mathrm{~h}$, and $0.30(0.70)$ and $1.81(0.54) \mathrm{mmol} \mathrm{h} \mathrm{l}^{-1}(p=0.084)$, respectively, for $\Delta \mathrm{AUC}_{12-24 \mathrm{~h}}$. The overall change in clamp glucose concentration $\left(\triangle \mathrm{AUC}_{0-24 \mathrm{~h}}\right)$ was not significantly different between BIAsp 30 and IGlarg (0.63 [0.79] and $2.41[0.86] \mathrm{mmol} \mathrm{h} \mathrm{l}{ }^{-1}$, respectively; $p=0.16$ ).

\section{Glucose infusion rate}

Mean GIR profiles are shown in Fig. 2a. As expected, BIAsp 30 and IGlarg exhibited quite different GIR profiles. After each injection of BIAsp 30, GIR increased rapidly for the first hour, reaching a peak value approximately $4 \mathrm{~h}$ after administration, following which the GIR slowly decreased. After s.c. injection of IGlarg the GIR increased, reaching a maximum value approximately $12 \mathrm{~h}$ after injection. Overall values for maximum GIR and $t_{\max }(0-24 \mathrm{~h})$ (Table 1) were higher for BIAsp 30 than for IGlarg. These differences were reflected in the greater glucose consumption with BIAsp 30 than IGlarg within the periods $0-12$ and $12-24 \mathrm{~h}$ (Table 1). The glucose-lowering response $\left(\mathrm{AUC}_{0-24 \mathrm{~h}}\right)$ for BIAsp 30 was $34 \%$ greater than for IGlarg $(p=0.037)$ for the full 24-h study period (Table 1).

\section{Plasma insulin profiles}

Fasting plasma insulin concentrations were similar on the BIAsp 30 and IGlarg study days $(80.9 \pm 14.8$ and $98.6 \pm$ $17.2 \mathrm{pmol} / \mathrm{l}$, respectively). The mean plasma insulin profiles are presented in Fig. 2b. As expected, two distinct peaks followed the two injections of BIAsp 30 compared with the flatter insulin profile with IGlarg. Peak plasma

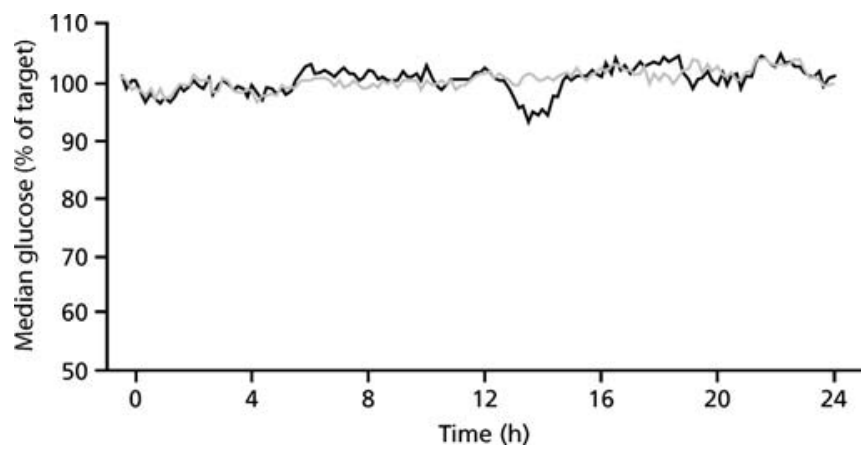

Fig. 1 Median plasma glucose (expressed as percentage of target) during the 24-h clamp period following injection of $0.5 \mathrm{U} / \mathrm{kg}$ BIAsp 30 twice daily (black line) or IGlarg once daily (grey line) 

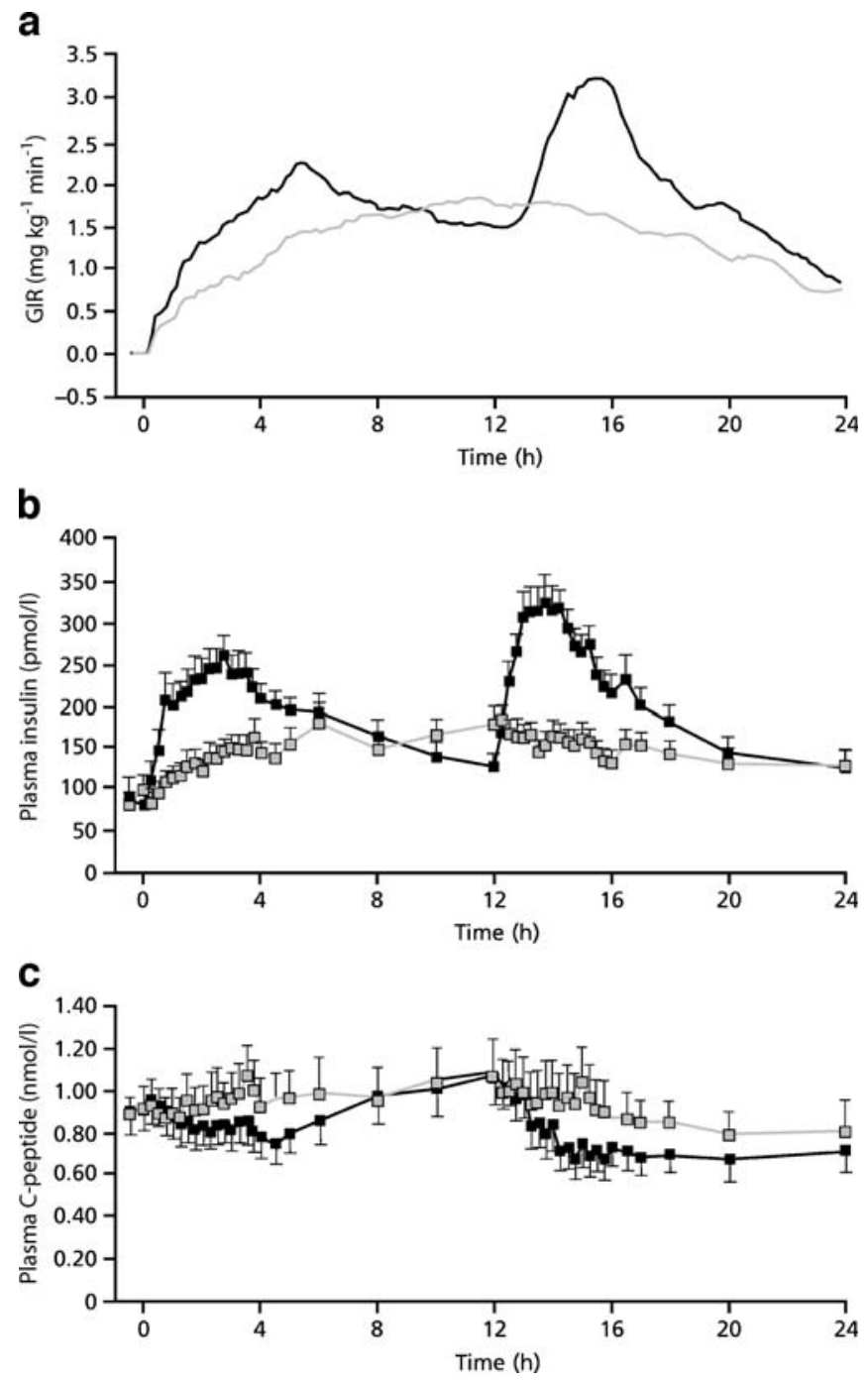

Fig. 2 Mean GIR $\left(\mathrm{mg} \mathrm{kg}^{-1} \mathrm{~min}^{-1}\right)$ (a) and mean ( \pm SEM) plasma insulin (pmol/l) (b) and plasma C-peptide (nmol/l) (c) during the 24-h clamp period following injection of $0.5 \mathrm{U} / \mathrm{kg}$ BIAsp 30 twice daily (black line) or IGlarg once daily (grey line)

insulin concentrations were achieved approximately $2-3 \mathrm{~h}$ after each injection of BIAsp 30 (Table 1, Fig. 2b). IGlarg achieved plateau plasma insulin concentrations approximately $6-16 \mathrm{~h}$ after the morning injection. The overall area under the plasma insulin profile $\left(\mathrm{AUC}_{0-24 \mathrm{~h}}\right)$ was $28 \%$ ( $p=0.001$ ) higher for BIAsp 30 than for IGlarg, reflecting the increased insulin concentrations observed soon after administration during the periods $0-12 \mathrm{~h}$ and $12-24 \mathrm{~h}$ (Table 1 ).

The estimated circulating exogenous plasma insulin $\left(\mathrm{AUC}_{0-24 \mathrm{~h}}\right)$ and bioavailability were twice as high $(105 \%$ greater) for BIAsp 30 as they were for insulin IGlarg (Table 1).

\section{Plasma C-peptide}

Plasma C-peptide concentrations were unchanged following the s.c. injection of IGlarg but fell below baseline relatively early after both injections of BIAsp 30 (Fig. 2c).
Over the total clamp period, the $\mathrm{AUC}_{0-24 \mathrm{~h}}$ for C-peptide was significantly lower for BIAsp 30 than for IGlarg $(p<0.029)$ (Table 1).

\section{Discussion}

For persons with type 2 diabetes failing on oral agents there is a need for the introduction of insulin in order to control glycaemia adequately; however, there is no agreed optimal mode of insulin regimen. The usual options are to include the use of premixed insulins either with [6] or without [7] oral agents or to use a basal insulin also with [5] or without oral agents, with the further option to add prandial insulin if and when required. Although overall similar reductions in $\mathrm{HbA}_{1 \mathrm{c}}$ may be achieved by these two options, there may be substantial differences in the number of hypoglycaemic episodes observed between treatment regimens.

Our study involved 12 males with type 2 diabetes on treatment with OHAs. Whereas it is common practice in many centres to continue therapy with OHAs (particularly metformin) when starting insulin therapy, these drugs were discontinued during the clamp study days. The OHAs were stopped the night before each clamp study day in order to better understand the time-action characteristics of the insulins without the potential confounding effects of these preparations. Unlike common practice, IGlarg was administered in the morning.

Subcutaneous injection of BIAsp 30 resulted in rapid absorption, a pronounced peak GIR being reached approximately $3-5 \mathrm{~h}$ after each injection due to the rapidacting, soluble insulin component of the premixed insulin preparation, followed by a prolonged decline in the GIR. Although the peak responses following each BIAsp 30 injection were similar, the second peak was considerably greater than the first, and this was reflected in a mean fall in plasma glucose concentration of $7-8 \%$ for $1-2 \mathrm{~h}$ after the second injection. This was caused by inadequate compensation of the glucose infusion rate, allowing the clamp to 'escape' during this period. However, had the GIR been adjusted to maintain fasting glucose concentrations, the second peak would have been even more exaggerated. In clinical use, to avoid nocturnal hypoglycaemic episodes it would be better to split the dose into two-thirds in the morning and one-third in the evening. As expected, the GIR response following IGlarg was very different. In this case the GIR rose gradually to a maximum effect approximately $12 \mathrm{~h}$ after injection, before returning very slowly towards baseline values at the end of the clamp period and in all but one patient the glucose infusion was still continuing at $24 \mathrm{~h}$. For equivalent doses, therefore, the overall glucose-lowering effect of BIAsp 30 was significantly greater than that of IGlarg.

Plasma insulin concentrations reflected the GIR. Plasma insulin rose rapidly after each injection of BIAsp 30, reaching a peak within 2-3 h after injection. In this way, BIAsp 30 approached the desired serum insulin profile for the purpose of controlling postprandial glucose [9]. However following the rapid increase in plasma insulin 
Table 1 Comparison of pharmacodynamic and pharmacokinetic parameters for BIAsp 30 and insulin glargine (IGlarg)

\begin{tabular}{|c|c|c|c|c|c|}
\hline Parameter & Time (h) & BIAsp 30 & IGlarg & $\begin{array}{l}\text { Difference (BIAsp } \\
\text { 30-IGlarg) }\end{array}$ & $p$ value \\
\hline \multicolumn{6}{|l|}{ GIR } \\
\hline \multirow[t]{3}{*}{ AUC $(\mathrm{g} / \mathrm{kg})$} & $0-12$ & $1.13 \pm 0.15$ & $0.91 \pm 0.07$ & $0.21 \pm 0.12$ & 0.099 \\
\hline & $12-24$ & $1.38 \pm 0.22$ & $0.96 \pm 0.07$ & $0.42 \pm 0.16$ & 0.022 \\
\hline & $0-24$ & $2.52 \pm 0.36$ & $1.87 \pm 0.12$ & $0.64 \pm 0.26$ & 0.037 \\
\hline \multirow[t]{3}{*}{$C_{\max }\left(\mathrm{mg} \mathrm{kg}^{-1} \min ^{-1}\right)$} & $0-12$ & $2.39 \pm 0.38$ & - & - & - \\
\hline & $12-24$ & $3.65 \pm 0.74$ & - & - & - \\
\hline & $0-24$ & $3.65 \pm 0.74$ & $2.01 \pm 0.16$ & $1.64 \pm 0.58$ & 0.017 \\
\hline \multirow[t]{3}{*}{$t_{\max }(\mathrm{h})$} & $0-12$ & $4.96 \pm 0.71$ & - & - & - \\
\hline & $12-24$ & $15.04 \pm 0.26$ & - & - & - \\
\hline & $0-24$ & $15.04 \pm 0.26$ & $12.0 \pm 1.00$ & $3.04 \pm 0.91$ & 0.007 \\
\hline \multicolumn{6}{|l|}{ Insulin } \\
\hline \multirow[t]{3}{*}{ AUC (pmol h $\left.1^{-1}\right)$} & $0-12$ & $2166 \pm 205$ & $1807 \pm 193$ & $358 \pm 99$ & 0.005 \\
\hline & $12-24$ & $2349 \pm 210$ & $1713 \pm 189$ & $2349 \pm 136$ & 0.001 \\
\hline & $0-24$ & $4514 \pm 404$ & $3521 \pm 368$ & $994 \pm 206$ & 0.001 \\
\hline \multirow[t]{3}{*}{$C_{\max }(\mathrm{pmol} / \mathrm{l})$} & $0-12$ & $285.3 \pm 26.8$ & - & - & - \\
\hline & $12-24$ & $369.5 \pm 30.1$ & - & - & - \\
\hline & $0-24$ & $373.2 \pm 30.7$ & $216.2 \pm 22.8$ & $157.0 \pm 20.5$ & $<0.001$ \\
\hline \multirow[t]{3}{*}{$t_{\max }(\mathrm{h})$} & $0-12$ & $2.44 \pm 0.13$ & - & - & - \\
\hline & $12-24$ & $14.08 \pm 0.16$ & - & - & - \\
\hline & $0-24$ & $13.04 \pm 1.04$ & $8.75 \pm 1.56$ & $4.29 \pm 1.64$ & 0.026 \\
\hline \multicolumn{6}{|l|}{ Exogenous insulin ${ }^{a}$} \\
\hline \multirow[t]{3}{*}{ AUC (pmol h 1 $\left.1^{-1}\right)$} & $0-12$ & $1165 \pm 64$ & $637 \pm 110$ & $528 \pm 126$ & 0.002 \\
\hline & $12-24$ & $1523 \pm 70$ & $672 \pm 97$ & $851 \pm 116$ & $<0.001$ \\
\hline & $0-24$ & $2689 \pm 116$ & $1309 \pm 180$ & $1379 \pm 220$ & $<0.001$ \\
\hline \multicolumn{6}{|l|}{ C-peptide } \\
\hline \multirow[t]{3}{*}{$\mathrm{AUC}\left(\mathrm{nmol} \mathrm{h} 1^{-1}\right)$} & $0-12$ & $10.91 \pm 1.30$ & $11.85 \pm 1.65$ & $-0.95 \pm 0.43$ & 0.051 \\
\hline & $12-24$ & $8.84 \pm 1.13$ & $10.51 \pm 1.43$ & $-1.67 \pm 0.67$ & 0.032 \\
\hline & $0-24$ & $19.74 \pm 2.39$ & $22.36 \pm 3.07$ & $-2.62 \pm 1.03$ & 0.029 \\
\hline $\begin{array}{l}\text { Relative bioavailability of plasma insulin } \\
\text { (BIAsp } 30 \text { vs IGlarg) }\end{array}$ & $128.2 \%$ & $95 \%$ CI $115.5-141.0 \%$ & & & \\
\hline $\begin{array}{l}\text { Relative bioavailability of exogenous plasma } \\
\text { insulin (BIAsp } 30 \text { vs IGlarg) }\end{array}$ & $205.4 \%$ & $95 \%$ CI $168.8-242.0 \%$ & & & \\
\hline
\end{tabular}

Data are means \pm SEM. ${ }^{a}$ Exogenous plasma insulin values calculated with negative values set to zero $C_{\max }$ maximum concentration; $t_{\max }$ time to reach maximum concentration

there was a slow decline towards baseline because of the intermediate-acting, protaminated IAsp component. Consistent with the previously demonstrated delayed and prolonged absorption of IGlarg [10], plasma insulin rose steadily from baseline after subcutaneous injection, reaching a maximum at $12 \mathrm{~h}$, before slowly returning to a concentration just above basal levels at the end of the 24-h clamp study period. The total estimated exogenous plasma insulin over this time $(0-24 \mathrm{~h})$ was significantly higher (28\%) after BIAsp 30 than after IGlarg for the same total daily dose given. The ratio of insulin to C-peptide used in this calculation was assumed to be constant [8]; however, it should be noted that non-steady-state conditions may apply since the clearance times of the two analytes differ substantially. Differences in the metabolic clearance rate of insulin via its receptor can influence plasma insulin concentrations and studies using in vitro cell lines [11] have indicated that insulin aspart has a slightly greater affinity for the insulin receptor than IGlarg (IAsp 0.92, IGlarg 0.86, relative to human insulin), which therefore could result in lower plasma BIAsp 30 insulin levels. The differences observed in the glucose-lowering effects of BIAsp 30 and IGlarg reflect the differences seen in the circulating insulin analogue profiles.

The residual endogenous insulin secretion, as reflected by the measured C-peptide concentration, was found to be significantly suppressed below baseline after each bolus injection of BIAsp 30 but was not seen following IGlarg administration. This observation may indicate that an acute prandial delivery of insulin, as seen with the BIAsp 30 analogue, protects the beta cell from excessive stimulation, a form of pancreatic beta cell 'rest'. There is evidence to suggest that by reducing the demand this may serve to support pancreatic beta cells and thereby slow the demise of the beta cell in people with type 2 diabetes [12]. Postprandial hyperglycaemia is acknowledged as an inde- 
pendent risk factor for macrovascular disease and mortality $[13,14]$. The results from the present study suggest that postprandial glucose excursions in people with type 2 diabetes would be more effectively controlled with BIAsp 30 than with the basal insulin IGlarg when given as monotherapy unsupported by OHAs with secretagogue properties [9]. In clinical practice, however, IGlarg is normally added to OHAs when these preparations, either as monotherapy or combination therapy, have failed to achieve the desired glycaemic targets. We await the publication of results of new clinical trials directly comparing IGlarg with BIAsp 30, both in combination with OHAs.

In summary, in people with type 2 diabetes, after an overnight fast the blood glucose-lowering effect and plasma insulin profile during a 24-h isoglycaemic clamp were approximately $30 \%$ greater following the subcutaneous administration of BIAsp $30(0.5 \mathrm{U} / \mathrm{kg})$ given as two split doses $12 \mathrm{~h}$ apart compared with IGlarg given as a single dose. The soluble component of BIAsp 30 was associated with acute and relatively short-lived suppression of endogenous insulin secretion, in contrast to IGlarg. This latter effect may help to delay the decline in beta cell function, and the early introduction of a meal-related insulin supplement in the treatment of type 2 diabetes may therefore be of advantage. Whereas the need for early insulinisation in people with type 2 diabetes inadequately controlled by lifestyle changes or oral agents is now well accepted, the debate about the selection of an insulin preparation for the initiation of therapy will undoubtedly continue. At this stage of treatment the choice between using a premix or basal insulin with or without concomitant oral agents should be determined according to the needs and circumstances of the individual. Results from this study illustrate the pharmacokinetic and pharmacodynamic characteristics of these two categories of insulin preparation.

Acknowledgements We are grateful to A. Clark, M. Evans, H. Smith and N. Williams for nursing and technical support.

Duality of interest statement D. R. Owens has received honoraria for lectures from Novo Nordisk and Sanofi-Aventis. This study was supported by Novo Nordisk.

\section{References}

1. Turner R, Cull C, Frighi V, Holman R (1999) Glycaemic control with diet, sulphonylureas, metformin, or insulin in patients with type 2 diabetes: progressive requirement for multiple therapies (UKPDS). UK Prospective Diabetes Study (UKPDS) Group. JAMA 281:2005-2012

2. UK Prospective Diabetes Study Group (1998) Intensive bloodglucose control with sulphonylureas or insulin compared with conventional treatment and risk of complications in people with type 2 diabetes mellitus. Lancet 352:837-853

3. Nathan DM (2002) Initial management of glycaemia in type 2 diabetes mellitus. N Engl J Med 347:1342-1349

4. Owens DR, Zinman B, Boli GB (2001) Insulins today and beyond. Lancet 358:739-746

5. Riddle MC, Rosenstock J, Gerich J, Insulin Glargine 4002 Study Investigators (2003) The treat-to-target trial: randomized addition of glargine or human NPH insulin to oral therapy of type 2 diabetic patients. Diabetes Care 26:3080-3086

6. Raskin P, Allen E, Hollander P, Lewin A, Gabbay RA, Hu P et al, INITIATE Study Group (2005) Initiating insulin therapy in type 2 diabetes: a comparison of biphasic and basal insulin analogs. Diabetes Care 28:260-265

7. Janka HU, Plewe G, Riddle MC, Kliebe-Frisch C, Schweitzer MA, Yki-Jarvinen H (2005) Comparison of basal insulin added to oral agents versus twice-daily premixed insulin as initial insulin therapy for type 2 diabetes. Diabetes Care 28:254-259

8. Owens DR (1986) Human insulin: clinical pharmacological studies in normal man. MTP Press, Lancaster, UK

9. Hermansen K, Colombo M, Storgaard H et al (2002) Improved postprandial glycaemic control with biphasic insulin aspart relative to biphasic insulin lispro and biphasic human insulin in patients with type 2 diabetes. Diabetes Care 25:883-888

10. Lepore M, Pampanelli S, Fanelli C et al (2000) Pharmacokinetics and pharmacodynamics of subcutaneous injection of long-acting human insulin analog glargine, NPH insulin, and ultralente human insulin and continuous subcutaneous infusion of insulin lispro. Diabetes 49:2142-2148

11. Kurtzhals P, Schäffer L, Sørensen A et al (2000) Correlations of receptor binding and metabolic and mitogenic potencies of insulin analogs designed for clinical use. Diabetes 49:999-1005

12. Buchanan TA (2003) Pancreatic beta-cell loss and preservation in type 2 diabetes. Clin Ther 25(Suppl B):B32-B46

13. Gerich JE (2003) Clinical significance, pathogenesis, and management of postprandial hyperglycaemia. Arch Intern Med 163:1306-1316

14. The DECODE Study Group, on behalf of the European Diabetes Epidemiology Group (1999) Glucose tolerance and mortality: comparison of WHO and American Diabetes Association Diagnostic criteria, the DECODE Study Group, European Diabetes Epidemiology Group: diabetes epidemiology: collaborative analysis of diagnostic criteria in Europe. Lancet 354: $617-621$ 